\title{
Viver o teatro como prática criativa e reflexão crítica
}

\author{
Maria Helena Serôdio
}

Neste número da revista, que assim completa o seu sexto ano de publicação, encontramos testemunhos e reflexões sobre o que tem sido o trabalho que por cá se faz no teatro e na investigação sobre teatro, cobrindo actuações diversas e recolhendo ecos importantes dessas práticas. E neste encontro de procedimentos de vida, investimentos artísticos e reflexão crítica pode medir-se a importância deste campo na respiração cultural do país.

Por esta razão, não poderia começar esta apresentação sem assinalar o luto que marcou, de forma trágica, o teatro português neste ano. Morreram - de ataque súbito e fulminante - ao sair do palco, a jovem actriz Ana Margarida Pereira e o actor Jorge Vasques respectivamente, nos espectáculos Agosto em Osage, sobre texto de Tracy Letts, estreado a 21 de Julho no Teatro Nacional D. Maria II, e 0 feio, sobre texto de Marius von Mayenburg, que a Assédio estreara em 19 de Setembro no Teatro Helena Sá e Costa, no Porto.

Três outros actores de longa e brilhante carreira, e de perfil diverso, enlutaram também a classe: Dalila Rocha que, tendo-se estreado no Teatro Experimental do Porto em 1953, veio a integrar o Teatro da Cornucópia vinte anos depois, retirando-se de cena em 1985, ano em que integrou o elenco de Ricardo III, de Shakespeare; Morais e Castro que, tendo dirigido o Cénico de Direito (da Universidade de Lisboa), teve estreia profissional em 1956 no Teatro do Gerifalto, vindo a integrar o Grupo 4 (entre 1969 e 1980), tornando-se mais conhecido do grande público por interpretar o papel do professor nas Lições do Tonecas na televisão, no final dos anos 90, veio ainda a distinguir-se no espectáculo 0 fazedor de teatro', uma produção da Companhia de Teatro de Almada que recebeu uma Menção Especial da Crítica (APCT) em 2004; e Raul Solnado, um dos actores portugueses mais populares e amados do século $X X$, a quem devemos expressões, ditos e graças que enriqueceram o nosso léxico gestual e linguistico e que prolongam a sua presença entre nós enquanto formos vivos, nós que o conhecemos como actor desde inícios dos anos 50 - e quantas vezes o "imitamos" -, mas que se tornou central na nossa vida teatral com a construção do Teatro Villaret, que protagonizou, e com o papel fulcral que desempenhou nos programas televisivos Zip Zip e Visita da Cornélia. Sobre ele escreveu para esta nossa revista a actriz e professora Ana de Carvalho, destacando o seu protagonismo no Teatro Villaret entre 1965 e1974 (n. 5, Junho de 2006, pp.121-128) e declarando, com inteira razão, que "ele se tornou parte importante da memória cultural do nosso pais" e que no projecto do Teatro Villaret se pode identificar "uma forma de transformação cultural" (p. 121), como, justamente, demonstrou nesse seu artigo ${ }^{2}$.

Dois outros vultos maiores do teatro português terminaram a sua carreira/vida neste ano, quando tinham entre mãos importantes projectos de encenação: Isabel Alves Costa e Mário Barradas. Cada um, a seu modo, contribuiu de forma decisiva para a transformação da própria vida institucional do teatro português. Isabel Alves Costa, para além dos seus trabalhos de investigação em teatro e de pontuais trabalhos de actriz, foi decisiva sobretudo pela fundação do Festival de Marionetas do Porto (em 1989) e pela política que pôde realizar enquanto directora do Rivoli Teatro Municipal, acção que foi brutalmente interrompida pela intervenção do Presidente da Câmara do Porto. Dela nos fala o artigo que Paulo Eduardo Carvalho publica neste número da revista "As curvas do futuro", mas dela pudemos ter colaboração preciosa em números anteriores: "As artes do circo" (n. 3, Junho de 2005, pp. 49-56) e a co-responsabilidade (com Paulo Eduardo Carvalho) das entrevistas a João Paulo Seara Cardoso, do Teatro de Marionetas do Porto, e André Braga e Cláudia Figueiredo, da companhia Circolando (Sinais de cena, n. ${ }^{\circ}$ 4, Dezembro de 2004, pp. 53-64, e n. ${ }^{8}$, Dezembro de 2007, pp. 49-58.). A Mário Barradas, professor devotado, encenador esclarecido e arguto, homem de teatro dos sete costados, fica o teatro português a dever muito do ponto de vista não apenas institucional - com a criação do Centro Cultural de Évora logo no início de 1975, assim lançando a ideia de que seria imperioso criar centros culturais que dinamizassem o teatro e a cultura em geral em todo o território nacional -, mas também como formador de várias gerações de artistas e como criador de espectáculos marcantes da história do teatro português: A grande imprecação diante das muralhas da cidade (1974), Auto da Lusitânia (1993), Tudo bem o que bem acaba (1994), entre tantos outros. A ele se devem ainda linhas importantes da definição legislativa e de reflexão civica sobre teatro, como bem se depreende de, entre outras fontes, 25 anos em cena: CCE / CENDREV 1975-2000 (organizado por Carlos Alberto Machado) e Mário Barradas: Um homem no teatro (2006). Dele pudemos ter um testemunho "Na primeira pessoa", interpelado que foi por Christine Zurbach e José Alberto Ferreira, como "Um impenitente fazedor de teatro" (n. 7 , Junho de 2007, pp. 35-44).

Alguma informação de base sobre todos estes artistas encontra-se na CETbase, a base de dados sobre o teatro
Ver Miguel-Pedro Quadrio, "Thomas Bernard 'servido' por Joaquim Benite", Sinais de cena, n. 3 , Junho de 2005 pp. 18-20.

${ }^{2}$ A investigação que esteve na base deste artigo foi desenvolvida para a sua tese de Mestrado em Estudos de Teatro, Raul Solnado e o Teatro Villaret. 
desenvolvida pelo Centro de Estudos de Teatro. E foi como extensão do compromisso deste centro com a investigação em teatro - nacional e internacional - nas suas perspectivas histórica e teórica, que o CET organizou a 52. Conferência Anual da FIRT-IFTR (Fédération Internationale pour la Recherche Théâtrale - International Federation for Theatre Research) na Faculdade de Letras da Universidade de Lisboa, de 14 a 17 de Julho, reunindo cerca de 500 intervenientes - entre professores, estudantes e investigadores de 41 paises, distribuidos pelos 5 continentes - sob o tema geral de "Vozes silenciosas / Vidas proibidas: A censura e o teatro". Nesse tema geral cabiam, entretanto, tópicos muito diversificados: "Drama sob escrutínio cerrado", "Géneros teatrais como respostas artísticas a constrangimentos ideológicos", "Dançar confrontos e compromissos", "Compor sobre o silêncio", "Políticas de género sob vigilância", "Corpos contra os limites", "Destruir as paredes e evadir-se do teatro", "Preparar o cenário para/contra o 'outro' reprimido", "Dissensões regionais, nacionais e intercontinentais", "Gritos de revolta deslocados e vozes de imigrantes", "Representar memórias ou a cultura contra a adversidade", "Desobediências teatrais", "Espectros do invisivel ou ausências fantasmáticas" e "Estratégias de sobrevivência sob os impérios".

De um vastíssimo acervo de comunicações e conferências (cerca de 300, a que se acrescentaram as muitas outras que decorreram em "ciclos" que coabitaram com a conferência principal, como é o caso do "Fórum dos novos investigadores" e os vários "Grupos de trabalho" permanentes da Federação ${ }^{3}$ ), recolhemos no "Dossiê

${ }^{3}$ Teatro africano, temático" deste número as treze que incidiram sobre a Teatro árabe, Arquitectura,

${ }^{4}$ Foi no contexto deste projecto que foram produzidos dois censura em Portugal, abarcando um arco temporal que vai desde o séc. XVII a 1974, antecedida pela conferência inaugural que esteve a cargo de Luiz Francisco Rebello. Considerámos também relevante acomodar nos "Estudos aplicados" a investigação que os classicistas da Faculdade de Letras da Universidade de Lisboa desenvolveram em torno do teatro grego a propósito do tema geral deste congresso, trazendo até nós interessantes reflexões sobre o teatro de Ésquilo, Eurípides e Aristófanes.

0 "Portefólio" reúne imagens de espectáculos que a romancista e dramaturga Hélia Correia (ela própria uma classicista de formação) tem "provocado", quer com peças originais, quer com adaptações várias, e que Ana Raquel Fernandes apresenta em breve texto introdutório.

Entretanto, "Na primeira pessoa" traz-nos a voz do jovem actor e encenador Gonçalo Amorim, de perfil muito próprio - já distinguido pela APCT pela sua encenação de Foder e ir às compras (2007) -, em conversa com Rui Pina Coelho, revelando as relações electivas e o pensamento próprio do seu itinerário artístico.

Outras vertentes do teatro em Portugal são recenseadas nas "Leituras" (a dramaturgia de Ruben A., um estudo sociológico da classe artística por Vera Borges, para além do livro de Isabel Alves Costa sobre o Rivoli) e nos "Passos em volta" - pelos artigos de Mónica Guerreiro,
Rui Pina Coelho e Constança Carvalho Homem -, surgem análises de espectáculos levados ao palco em Lisboa - no Teatro da Trindade, São Luiz Teatro Municipal, Centro Cultural de Belém e ZDB -, e, no Porto, duas produções, respectivamente, do Ensemble e da Assédio.

Escavando histórias de companhias ambulantes do séc. XIX em Portugal, o actor e investigador Guilherme Filipe dá delas um retrato de verdadeiro conhecedor - a que não falta verve e carinho, erguendo talvez uma bandeira de cumplicidade - no "Arquivo solto" deste número, enquanto do Brasil nos chega - pela escrita da investigadora e professora Ana Maria de Bulhões-Carvalho - uma interessante deambulação pelo teatro musical carioca que celebra artistas conhecidos.

De fora vêm ainda notícias de um espectáculo de Claude Régy sobre a Ode marítima (por Hélder Wasterlain) e uma experimentação que Hugo Miguel Coelho desenvolveu em torno da temática do "medo contemporâneo".

Assinalem-se, por último, referências neste número a dois outros vínculos com plataformas internacionais em que Portugal está representado por instituições portuguesas: o projecto plurianual $(2008$ - 2012) de cooperação cultural europeia "Próspero", que reúne as cidades de Lisboa (Centro Cultural de Belém), Liège, Bélgica (Théâtre de la Place), Rennes, França (Théâtre National de Bretagne), Modena, Itália (Fondazione Emilia Romagna), Berlim, Alemanha (Schaubühne am Lehniner Platz) e Tampere, Finlândia (Tutkivan Teatterityön Keskus) - e que foi responsável pela apresentação no CCB do espectáculo Hedda Gabler, encenado por Thomas Ostermeier, numa produção da Schaubühne ${ }^{4}$, referida no artigo de Mónica Guerreiro -, bem como a relação forte da APCT com a Associação Internacional de Críticos de Teatro (AICT) que pesou bastante na criação e desenvolvimento da revista semestral de suporte electrónico - Critical Stages/Scènes critiques - lançada em Outubro passado e aqui apresentada na secção "Em rede".

Mas de outros vínculos, outras memórias e outras cumplicidades é feita a vida desta nossa revista, pelo que, uma vez mais, lembramos não apenas os autores dos artigos que generosamente contribuíram com o seu saber e trabalho para que ela aqui se reconfigurasse no que é este número, mas também as muitas outras ajudas que firmam a sua existência: os dois Teatros Nacionais, que aceitaram publicitar aqui as suas temporadas, e os muitos fazedores (investigadores e funcionários de instituições) de teatro que incansavelmente nos apoia(ra)m em quase tudo: informações, textos de apoio, fotografias, etc. Essa é uma cadeia que se vai tornando mais forte e visivel, dando conta de uma respiração convergente onde estão, seguramente, muitos dos que antes de nós foram fazendo este caminho. Como os que invocámos no início deste Editorial, e outros que os antecederam, e que nós - como elos circunstanciais - gostariamos de legar aos que vierem depois de nós. 